\title{
SÉANCE DU 28 JANVIER 1921
}

PRÉSIDENCE DE M. L. MANGIN.

Lecture est donnée du procès-verbal de la dernière séance, dont la rédaction est adoptée.

Par suite des présentations faites dans la dernière séance, M. le Président proclame membres de la Société :

MM. Chouard, étudiant, 10, rue de l'Est, à Melun (Seineet-Marne), présenté par MM. Camus et Jeanpert.

Dangeard (Pierre), préparateur à la Faculté des Sciences de Paris, présenté par MM. Guignard et Mangin.

M. le Président annonce ensuite deux nouvelles présentations.

M. Chermezon ayant accompli les formalités prescrites par les statuts est prợlamé membre à vie.

M. le Secrétaire général donne connaissance de la composition des commissions pour 1921. Il lit ensuite le rapport annuel sur la situation et les travaux de la Société, précédemment communiqué au Conseil qui l'a approuvé.

Commission de Comptabilité : MM. le prince Bonaparte, Giraudias, Guérin.

Commission des Archives : MM. Danguy, Dode, Fron.

Commission du Bulletin : MM. Bois, prince Bonaparte, Camus, Jeanpert, Souèges, Mangin et MM. les Membres du Secrétariat.

Comité consultatif pour la détermination des plantes : MM. Dangeard et Mangin (Algues); Patouillard et Dumée (Champignons); B. de Lesdain (Lichens); Camus et Dismier (Muscinées); Gagnepain et Jeanpert (Plantes vasculaires); Battandier et Pitard (Plantes de l'Afrique du Nord).

Commission de la Session: MM. Allorge, Camus, Hibon.

Commission des Élections : MM. le Premier Vice-Président, le Trésorier et l'Archiviste.

Commission du Prix de Coincy : MM. les anciens Présidents et MM. Camus et Danguy, membres élus. 


\section{$2 \mathrm{BHL}$ Biodiversity Heritage Library}

1921. "Séance Du 28 Janvier 1921." Bulletin de la Société botanique de France 68, 51-51. https://doi.org/10.1080/00378941.1921.10836739.

View This Item Online: $\underline{\text { https://www.biodiversitylibrary.org/item/93710 }}$

DOI: https://doi.org/10.1080/00378941.1921.10836739

Permalink: https://www.biodiversitylibrary.org/partpdf/161190

\section{Holding Institution}

Missouri Botanical Garden, Peter H. Raven Library

\section{Sponsored by}

Missouri Botanical Garden

\section{Copyright \& Reuse}

Copyright Status: Public domain. The BHL considers that this work is no longer under copyright protection.

This document was created from content at the Biodiversity Heritage Library, the world's largest open access digital library for biodiversity literature and archives. Visit BHL at https://www.biodiversitylibrary.org. 